OPEN ACCESS

Edited by:

Ruan Kruger,

North-West University, South Africa

Reviewed by:

Mieczyslaw Litwin

Children's Memorial Health Institute

(IPCZD), Poland

Peter Mikael Nilsson,

Lund University, Sweden

*Correspondence:

Elaine M. Urbina

elaine.urbina@cchmc.org

Specialty section:

This article was submitted to

Pediatric Cardiology,

a section of the journal

Frontiers in Pediatrics

Received: 22 September 2021

Accepted: 29 October 2021

Published: 29 November 2021

Citation:

Madsen NL, Haley JE, Moore RA, Khoury PR and Urbina EM (2021)

Increased Arterial Stiffness Is Associated With Reduced Diastolic

Function in Youth With Obesity and

Type 2 Diabetes.

Front. Pediatr. 9:781496,

doi: 10.3389/fped.2021.781496

\section{Increased Arterial Stiffness Is Associated With Reduced Diastolic Function in Youth With Obesity and Type 2 Diabetes}

\author{
Nicolas L. Madsen ${ }^{1}$, Jessica E. Haley ${ }^{2}$, Ryan A. Moore ${ }^{3}$, Philip R. Khoury ${ }^{3}$ and \\ Elaine M. Urbina ${ }^{3 *}$ \\ 1 Department of Pediatrics, University of Texas Southwestern Medical Center, Dallas, TX, United States, ${ }^{2}$ Department of \\ Pediatrics, Rady Children's Hospital, San Diego, CA, United States, ${ }^{3}$ The Heart Institute, Cincinnati Children's Hospital \\ Medical Center and the University of Cincinnati, Cincinnati, $\mathrm{OH}$, United States
}

Background: Increased arterial stiffness is associated with diastolic dysfunction in adults. Data in youth are lacking, so we examined the impact of arterial stiffness on diastolic function in youth.

Methods: We obtained diastolic function and augmentation index, pulse wave velocity, brachial artery distensibility, and carotid stiffness on 612 youth [10-24 years, 65\% female, 38\% normal weight, 36\% obese, and 26\% with type 2 diabetes mellitus (T2DM)]. Participants were classified as compliant (C) vs. stiff (S) arteries based on seven arterial stiffness parameters [Global Stiffness Index (GSI), $S=G S I>4$ ). Mean differences in covariates were evaluated by Student's $t$-tests. A stepwise regression analysis was performed to determine if GSI was an independent predictor of diastolic function.

Results: Lower diastolic function and more adverse cardiovascular disease (CVD) risk factors were present in the S group $(n=67)$ than the C group $(n=545)(p<0.001)$. Covariates that were associated with diastolic dysfunction were higher GSI, male sex, higher body mass index (BMI), and systolic blood pressure (SBP) $z$-score $\left(R^{2}=0.18\right.$ to $0.25 ; p \leq 0.05)$.

Conclusion: Adverse diastolic function is seen in youth with increased arterial stiffness independent of CVD risk factors. Interventions to improve arterial stiffness prior to clinical onset of diastolic dysfunction are needed to prevent development of heart failure.

Keywords: arterial stiffness, diastolic dysfunction, pediatrics, obesity, T2DM

\section{INTRODUCTION}

Effective cardiovascular disease (CVD) prevention requires identification of risk factors prior to the onset of clinical burden. While it is commonly understood that adults with obesity or obesityrelated type 2 diabetes mellitus (T2DM) are at increased risk for CVD (1), the evidence regarding the extent to which these risk factors impact the pediatric age range is not well-characterized.

Diastolic dysfunction is a risk factor-related measure of target organ damage that predicts heart failure $(2,3)$ and $\mathrm{CV}$ events in adults (4). Emerging evidence suggests that pre-clinical diastolic dysfunction [diastolic dysfunction with normal systolic function and without symptoms of heart 
failure (5)] exists in hypertensive adolescents (6) and youth with obesity or T2DM (7). One mechanism for the development of diastolic dysfunction may be increased afterload on the heart induced by increased arterial stiffness $(8,9)$. Pediatric studies show that arterial damage is associated with higher left ventricular mass (10) and with reduced systolic strain (11). We sought to determine the relationship between arterial damage and diastolic function in healthy youth and those with CV risk factors including obesity and T2DM.

\section{METHODS}

The study population consisted of 612 youth (age 10-24 years, mean 18 years, 65\% female, 62\% non-Caucasian, and 26\% with T2DM) who participated in a study comparing cardiovascular parameters among adolescents and young adults who were lean $(\mathrm{L})$, obese $(\mathrm{O})$, or obese with T2DM (T). Pregnant females were excluded from the study. Investigational review board approval was obtained. Written informed consent was obtained from subjects 18 years or older and from the guardian for subjects $<18$ years old. Written assent was obtained for subjects $<18$ years old.

\section{Risk Factor Measurements}

The mean of two measures of height with a calibrated stadiometer (Veeder-Rood, Elizabethtown, North Carolina) and two measures of weight with a Health-O-Meter electronic scale (Jarden Consumer Solutions, Rye, New York) were used in analyses. Body mass index (BMI) was calculated as weight (kilograms) / height (meter) (2). The mean of three resting measures of blood pressure (BP) with mercury sphygmomanometry collected after $5 \mathrm{~min}$ of rest according to pediatric guidelines (12) was obtained. After an overnight fast, plasma glucose was measured with a Hitachi model 704 glucose analyzer (Roche Hitachi, Indianapolis, Indiana) with intraassay and inter-assay coefficients of variation of 1.2 and $1.6 \%$, respectively. Plasma insulin was measured by radioimmunoassay with an anti-insulin serum raised in guinea pigs, indium125labeled insulin (Linco, St. Louis, Missouri), and a doubleantibody method to separate bound from free tracer with a sensitivity of $2 \mathrm{mmol}$ (intra-assay and inter-assay coefficients of variation of 5 and $8 \%$, respectively). Glycated hemoglobin A1c (HbA1c) was measured by use of high-pressure liquid chromatography. Fasting plasma lipid profiles were performed with standardized methods from the National Heart Lung and Blood Institute-Centers for Disease Control and Prevention, and low-density lipoprotein cholesterol concentration was calculated with the Friedewald equation. C-reactive protein (CRP) was measured with a high-sensitivity enzyme-linked immunosorbent assay.

\section{Arterial Stiffness Measurements}

Vascular function testing was conducted after 5 min of rest in the supine position. Three measures of brachial artery distensibility (BrachD) were obtained with a DynaPulse Pathway instrument (Pulse Metric, Inc., San Diego, California). This device derives brachial artery pressure curves from arterial pressure signals obtained from a standard cuff sphygmomanometer. Brachial artery compliance is derived from waveform parameters, and then BrachD is calculated as compliance normalized to baseline brachial artery diameter (estimated from a regression equation developed from ultrasound, adjusting for sex and body size). This variable is equivalent to other measures of distensibility, such as those measured with ultrasonography, in that it represents the relative change in volume per unit of pressure and is expressed with the units of $\%$ change $/ \mathrm{mmHg}$. Repeat measures in our laboratory show coefficients of variability $<9 \%$.

Three measures of pulse wave velocity (PWV) were measured and averaged with a SphygmoCor SCOR-PVx System (Atcor Medical, Sydney, Australia). PWV is a measure of the difference in the carotid-to-distal path length divided by the difference in R-wave-to-waveform foot times $(\mathrm{m} / \mathrm{s})$. Specifically, electrocardiography (ECG) leads were applied to the carotid artery, the sternal notch, and the distal artery of interest (femoral, radial, and dorsalis pedis). A pressure tonometer the size of a pencil is placed on the proximal artery (carotid) then distal to obtain arterial waveforms gated to the R-wave on the electrocardiography tracing. The ECG recording was used to measure heart rate. Repeat measures in our laboratory show coefficients of variability $<7 \%$.

Three measures of augmentation index (AIx) were collected with the SphygmoCor device. The pressure sensor is applied to the radial artery to collect radial artery pressure waves that are calibrated to a non-invasive blood pressure (Pulse Metric, Inc., San Diego, California). A generalized transfer function validated against invasive catheterization data is used to calculate central (aortic) systolic blood pressure (SBP), diastolic blood pressure (DBP), mean arterial pressure (MAP), and pulse pressure $(\mathrm{PP})$ and reconstruct the central aortic pressure curve. AIx, adjusted to a heart rate of 75 beats per minute, is calculated utilizing the ascending aorta pressure curve. AIx is the pressure difference between the primary (main outgoing wave) and the reflected wave of the central arterial waveform, expressed as a percentage of the central pulse pressure. Reproducibility studies in our laboratory demonstrated intra-class correlation coefficients between 0.7 and 0.9 for all variables.

\section{Carotid Ultrasonography}

Carotid ultrasound studies were performed by a single registered vascular technologist using high-resolution Bmode ultrasonography (GE Vivid 7; GE Healthcare, Milwaukee, Wisconsin) with a high-resolution linear array vascular transducer (7.5 MHz). An optimal two-dimensional (2D) image of the common carotid artery was obtained, where both the near and far wall intima/media complex were well-visualized. The M-mode cursor was then placed $1 \mathrm{~cm}$ proximal to the beginning of the carotid artery bulb. Multiple image loops were digitally transmitted by use of the Camtronics Medical System (Camtronics Medical Systems, Hartland, Wisconsin) for off-line reading. The maximal and minimal lumen diameters were read from the M-mode tracing for calculations of carotid stiffness. Calculations included arterial compliance (AC), beta stiffness index $(\beta)$, circumferential arterial strain (CAS), Peterson's elastic modulus (PEM), and Young's elastic modulus (YEM). Because of pulse-wave amplification along the arterial tree, which results 
in overestimation of brachial SBP, the central BP calculated from the radial artery pressure curve using the SphygmoCor device (obtained no more than $30 \mathrm{~min}$ before the carotid scan) was used in the calculations of carotid artery stiffness.

\section{Echocardiographic Technique}

Echocardiograms were obtained with a GE Vivid 5 or 7 (Milwaukee, WI, USA) or Philips Sonos 5500 (Andover, MA, USA) ultrasound system. A complete 2D pulsed Doppler, tissue Doppler, and color Doppler echocardiographic examination was performed on each participant. All images were obtained with the participant in the left lateral decubitus position to acquire parasternal long-axis, parasternal short-axis, and apical fourchamber views for a total of three cardiac cycles. Left atrial diameter (LAD) was measured in the long axis and indexed to height (LAD/ht). Measurement was performed off-line by either of two sonographers using a Cardiology Analysis System (Digisonics, Houston, TX, USA).

The assessment of mitral inflow velocity was obtained with pulsed wave Doppler parallel to mitral inflow in the apical fourchamber view, and maximal velocity measured at the mitral valve leaflet tips. The mitral peak $E$ (early filling) and $A$ (inflow with atrial contraction) waves were measured off-line, and an $E / A$ ratio was calculated. Tissue Doppler imaging of myocardial flow velocities was acquired in the apical four-chamber view. The peak and late velocities of mitral annular flow were recorded at both the septal annulus ( $e^{\prime}$-sept, $a^{\prime}$-sept) and lateral annulus ( $e^{\prime}$-lat, $a^{\prime}$-lat). The $e^{\prime} / a^{\prime}$ ratios were calculated in addition to $E / e^{\prime}-$ lat and $E / e^{\prime}$-sept ratios. The $E / e^{\prime}$ ratio corrects for myocardial relaxation in transmitral flow $(E)$ and has been shown to correlate with left ventricular (LV) end-diastolic pressure (7). In adults, an $E / e^{\prime}$-lat of $>10$ is predictive of elevated LV filling pressures, and $<6$ is normal. In addition, the left atrial size was assessed by two-dimensional-directed M-mode and indexed to height.

\section{Statistical Analysis}

All analyses were performed with Statistical Analysis Software (SAS ${ }^{\circledR}$, version 9.1.3, Cary, North Carolina). Variance-stabilizing measures to transform non-normal values were performed as needed. The 95th percentile for each of the seven arterial stiffness measures (BrachD, AIx, PWV, AC, $\beta$, CAS, PEM, and YEM) for lean subjects without diabetes was determined. Subjects were given a score of 1 for the parameter if $\geq 95$ th percentile for the lean group ( $\leq 5$ th percentile for $\mathrm{AC}$ and BrachD) and 0 if below the cutpoint (overall, a total of 7 points are possible). Global Stiffness Index (GSI) was calculated as the sum of the stiffness points for each of the four measures of carotid artery stiffness and the three non-ultrasound measures of arterial stiffness. The GSI has been shown to be linearly related to LV mass index in a previous study (10). Subjects were stratified into either "compliant arteries" (CA) or "stiff arteries" (SA) based on their GSI score (a score of 4 or greater, which was the 95th percentile for GSI for the lean, healthy group, qualified as stiff). Average values for demographic, anthropometric, BP, and laboratory values were obtained for each group. Student's $t$-tests were performed to determine differences by stiffness classification. The $\chi^{2}$ analyses were
TABLE 1 | Demographics and metabolic profile of study participants stratified by Global Stiffness Index category ( $n=612$, mean \pm SD or frequency).

\begin{tabular}{|c|c|c|c|}
\hline Variable & Compliant $(n=545)$ & Stiff $(n=67)$ & $P$ value \\
\hline Age (years) & $17.8 \pm 3.3$ & $19.5 \pm 3.2$ & $<0.01$ \\
\hline Sex (\% male) & 192 (35.2\%) & 18 (26.9\%) & NA \\
\hline Race (\% non-Caucasian) & $335(61.5 \%)$ & $46(68.6 \%)$ & NA \\
\hline Presence of T2DM (\%) & 127 (23.3\%) & 30 (44.8\%) & NA \\
\hline Weight (kg) & $87 \pm 31$ & $113 \pm 26$ & $<0.01$ \\
\hline Height (cm) & $167 \pm 11$ & $168 \pm 10$ & NS \\
\hline $\mathrm{BMI}\left(\mathrm{kg} / \mathrm{m}^{2}\right)$ & $31 \pm 10$ & $40 \pm 8$ & $<0.01$ \\
\hline $\mathrm{SBP}(\mathrm{mmHg})$ & $114 \pm 12$ & $124 \pm 12$ & $<0.01$ \\
\hline DBP (mmHg) & $63 \pm 12$ & $71 \pm 15$ & $<0.01$ \\
\hline HR (beats/min) & $66 \pm 11$ & $72 \pm 11$ & $<0.01$ \\
\hline TChol (mg/dl) & $169 \pm 35$ & $184 \pm 43$ & $<0.01$ \\
\hline LDL-C (mg/dl) & $99 \pm 29$ & $114 \pm 40$ & $<0.01$ \\
\hline HDL-C (mg/dl) & $50 \pm 13$ & $46 \pm 11$ & $<0.01$ \\
\hline TG (mg/dl) & $96 \pm 67$ & $126 \pm 73$ & $<0.01$ \\
\hline Fasting glucose (mg/dl) & $103 \pm 43$ & $123 \pm 70$ & $<0.01$ \\
\hline Fasting insulin (mU/ml) & $18 \pm 15$ & $23 \pm 12$ & $<0.01$ \\
\hline $\mathrm{HbA1c}(\%)$ & $5.97 \pm 1.8$ & $6.72 \pm 2.3$ & $<0.01$ \\
\hline hsCRP (mg/l) & $4 \pm 6.5$ & $6.5 \pm 7.3$ & $<0.01$ \\
\hline
\end{tabular}

$\overline{T 2 D M}=$ type 2 diabetes mellitus; $B M I=$ body mass index; $S B P=$ systolic blood pressure; $D B P=$ diastolic blood pressure; $H R=$ heart rate; $T C h o l=$ total cholesterol; $L D L-C=$ low density lipoprotein concentration; $H D L-C=$ high density lipoprotein concentration; $H b A 1 c=$ glycoselated hemoglobin; $h s C R P=$ high sensitivity $C$-reactive protein.

performed for categorical variables. Bivariate correlations were calculated for GSI, covariates, and diastolic function variables. Variables that were significant in the bivariate analysis were included as potential independent predictors in the general linear model analyses. The full model contained the following data: demographic (age, race/ethnicity, sex, and presence of T2DM), anthropometric (BMI $z$-score), hemodynamic (SBP $z$-score, DBP $z$-score, and HR), and laboratory (fasting glucose, fasting insulin, HbA1c, low-density lipoprotein cholesterol, high-density lipoprotein cholesterol, triglycerides, and CRP). The significance of each covariate in the initial model was assessed, and nonsignificant terms were removed by backward elimination until all remaining covariates or their interaction terms were significant. Robustness of the models was assessed with the use of the maximum $R$-square technique.

\section{RESULTS}

The population included 612 youth (10-24 years, 65\% female, and $62 \%$ non-Caucasian) enrolled in one of three groups $(38 \%$ lean, $36 \%$ obese without T2DM, and $26 \%$ obese with T2DM). When stratified as having compliant or stiff arteries (Table 1), participants with stiff arteries were older and more obese and had higher peripheral BP and heart rate, a more adverse lipid and metabolic profile, and more evidence of inflammation (all $p \leq 0.01)$. Specifically, lipids in the stiff group were within normal limits, but glucose, insulin, and HbA1c were elevated, since more diabetics were included in the group. Additionally, the 
stiff group had a mean SBP in the elevated BP category according to BP guidelines (12).

Consistent with stratification by GSI, the stiff cohort had arterial function measures (AIx, PWV, $\beta$, PEM, YEM, AC, CAS, and BrachD) that were in the direction of higher arterial stiffness (Table 2). The stiff group also had significantly lower $E / A$ ratio and $e^{\prime} / a^{\prime}$, as well as higher $E / e^{\prime}$, all suggesting pre-clinical diastolic

TABLE 2 | Cardiovascular parameters stratified by arterial stiffness category (mean $\pm \mathrm{SD}$ ).

\begin{tabular}{|c|c|c|c|}
\hline Variables & Compliant $(n=545)$ & Stiff $(n=67)$ & $P$ value \\
\hline \multicolumn{4}{|c|}{ Stiffness variables (means) } \\
\hline Alx (\%) & $1.65 \pm 11$ & $8.27 \pm 13$ & $<0.01$ \\
\hline BrachD $(\% \Delta / \mathrm{mmHg})$ & $6.15 \pm 1.3$ & $4.73 \pm 0.6$ & $<0.01$ \\
\hline $\mathrm{PWV}(\mathrm{m} / \mathrm{s})$ & $5.9 \pm 1$ & $7.3 \pm 1.2$ & $<0.01$ \\
\hline $\mathrm{AC}(\mathrm{mm} / \mathrm{mmHg})$ & $0.27 \pm 0.07$ & $0.20 \pm 0.06$ & $<0.01$ \\
\hline Beta (unitless) & $2.2 \pm 0.5$ & $2.9 \pm 0.9$ & $<0.01$ \\
\hline CAS (unitless) & $0.19 \pm 0.04$ & $0.16 \pm 0.05$ & $<0.01$ \\
\hline PEM (mmHg) & $192 \pm 65$ & $209 \pm 77$ & NS \\
\hline YEM (mmHg/mm) & $256 \pm 112$ & $403 \pm 150$ & $<0.01$ \\
\hline \multicolumn{4}{|l|}{ Diastolic variables } \\
\hline E/A ratio & $1.99 \pm 0.55$ & $1.76 \pm 0.43$ & $<0.01$ \\
\hline$e^{\prime} / a^{\prime}$ avg & $2.36 \pm 0.65$ & $1.91 \pm 0.48$ & $<0.01$ \\
\hline E/e' avg (LVEDP) & $6.47 \pm 1.43$ & $7.29 \pm 1.68$ & $<0.01$ \\
\hline LA diameter/ht (cm) & $1.98 \pm 0.32$ & $2.21 \pm 0.33$ & $<0.01$ \\
\hline
\end{tabular}

dysfunction (Table 2). There was a linear relationship between increasing levels of GSI (0-7) and lower diastolic function including increased LAD/ht (Figure 1) and between lower $E / A$ ratio (Figure 2) and $e^{\prime} / a^{\prime}$ (Figure 3). There was a similar increase in $E / e^{\prime}$ across GSI score (data not shown).

General linear models demonstrated that GSI was independently related to diastolic function $(p \leq 0.0001$ for $\mathrm{LAD} / \mathrm{ht}, E / A$, and $\left.e^{\prime} / a^{\prime}\right)$. Other important covariates associated with lower diastolic function were male sex, higher BMI and SBP $z$-score, age, LDL, CRP, and HR $\left(R^{2}=0.16\right.$ to 0.40 ; model $p \leq$ 0.001 and all parameters $p \leq 0.05$ ) (Table 3 ).

\section{DISCUSSION}

Our study findings demonstrate that higher arterial stiffness, independent of traditional CVD risk factors, is associated with lower diastolic function in youth. Importantly, these changes in youth are pre-clinical and represent an early form of cardiac disease that is measurable before most other traditional determinants of cardiac disease, such as overt heart failure.

Clinical symptoms of heart failure are common in the adult population, experienced by at least 6.2 million Americans according to American Heart Association data (1). However, many more adults may have asymptomatic diastolic dysfunction, with the prevalence in the Framingham Heart Study reported to be $36 \%$ (1). This is relevant since diastolic dysfunction is predictive of incident heart failure (3), reduced quality of life (13), and all-cause mortality $(3,5,14)$.

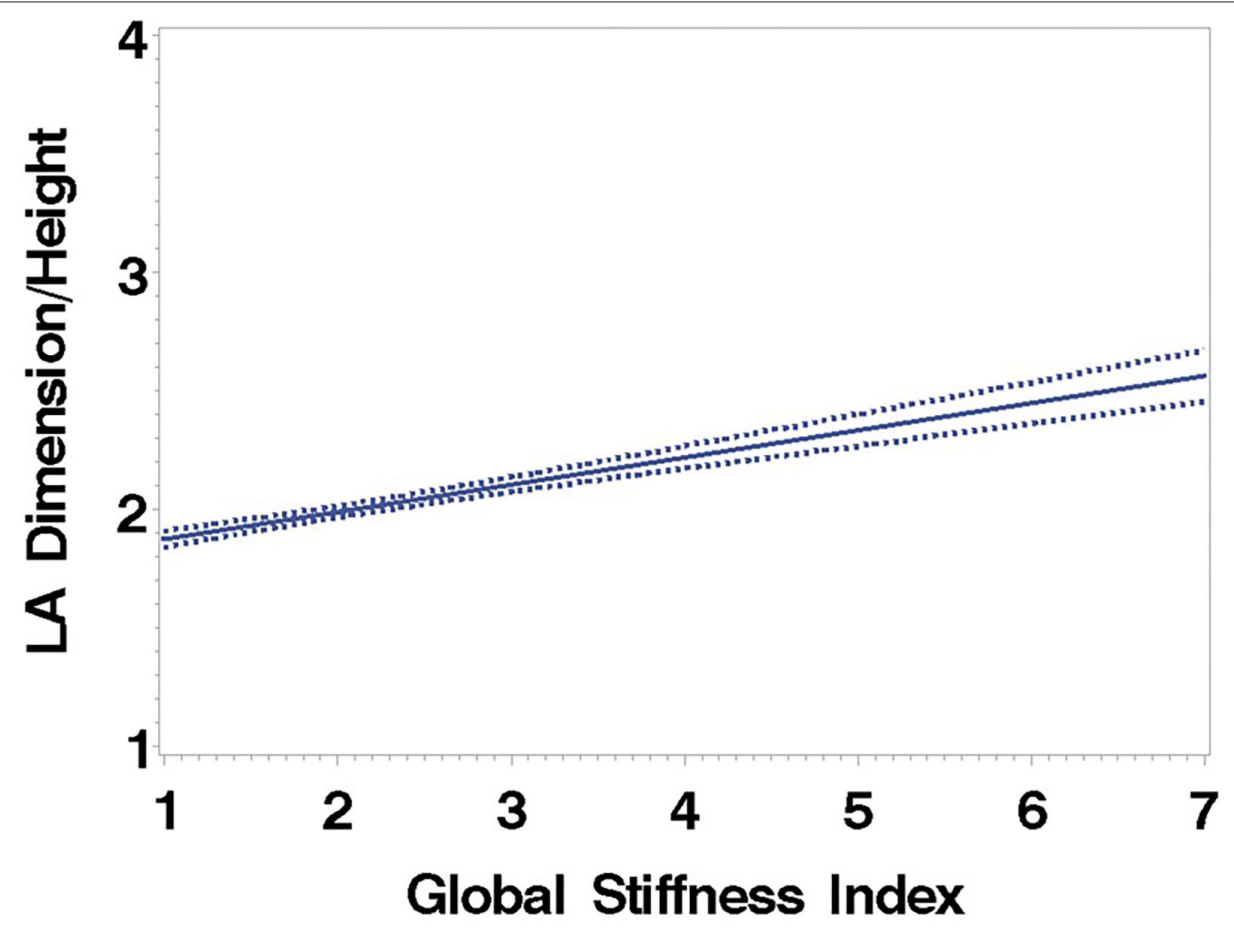

FIGURE 1 | Left atrial dimension/height regressed on the Global Stiffness Index (mean with 95\% confidence limit). $R^{2}=0.40$; $P$ for slope differs from zero $<0.0001$ in fully adjusted model. 


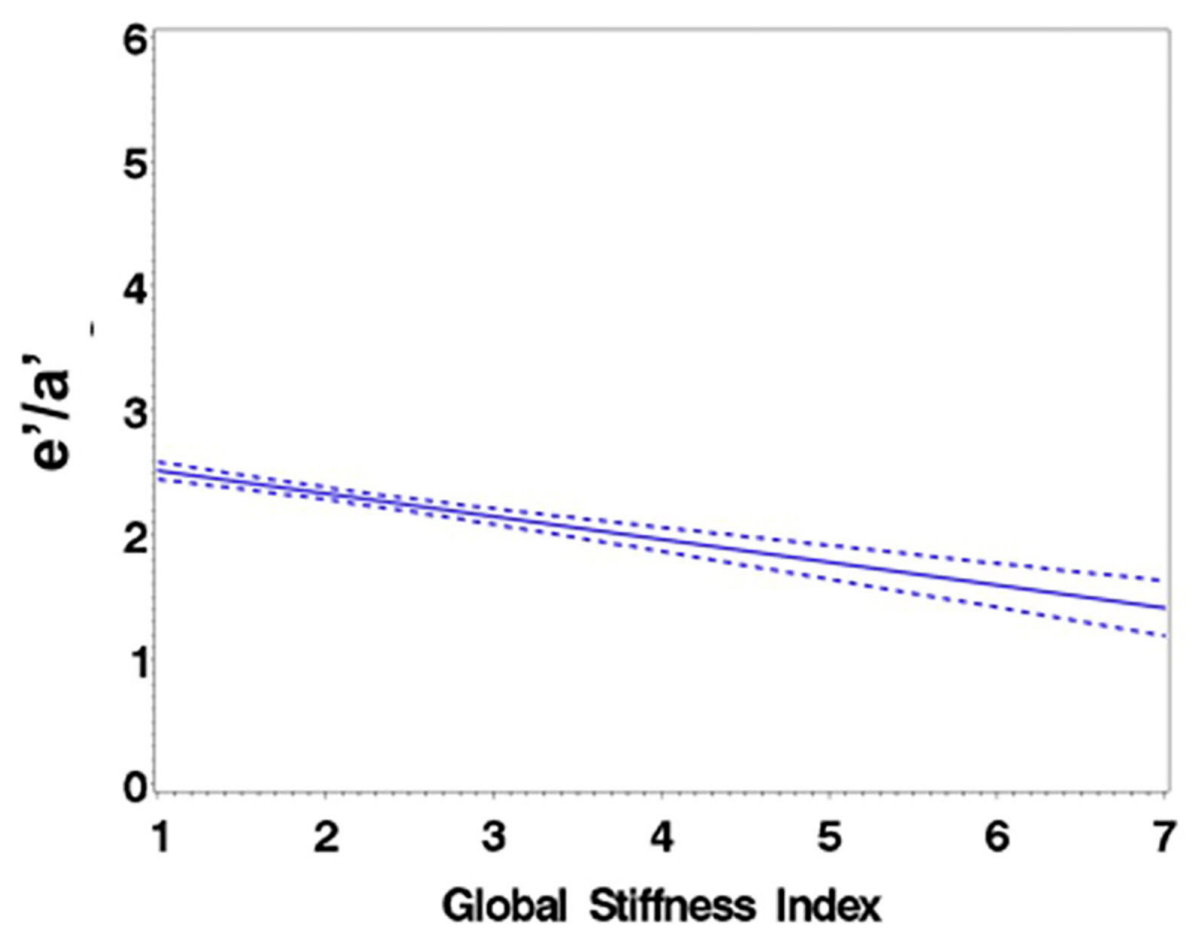

FIGURE 2 | Regression of E/A ratio on the Global Stiffness Index (mean with 95\% confidence limit). $R^{2}=0.16$; $P$ for slope differs from zero $<0.0001$ in fully adjusted model.

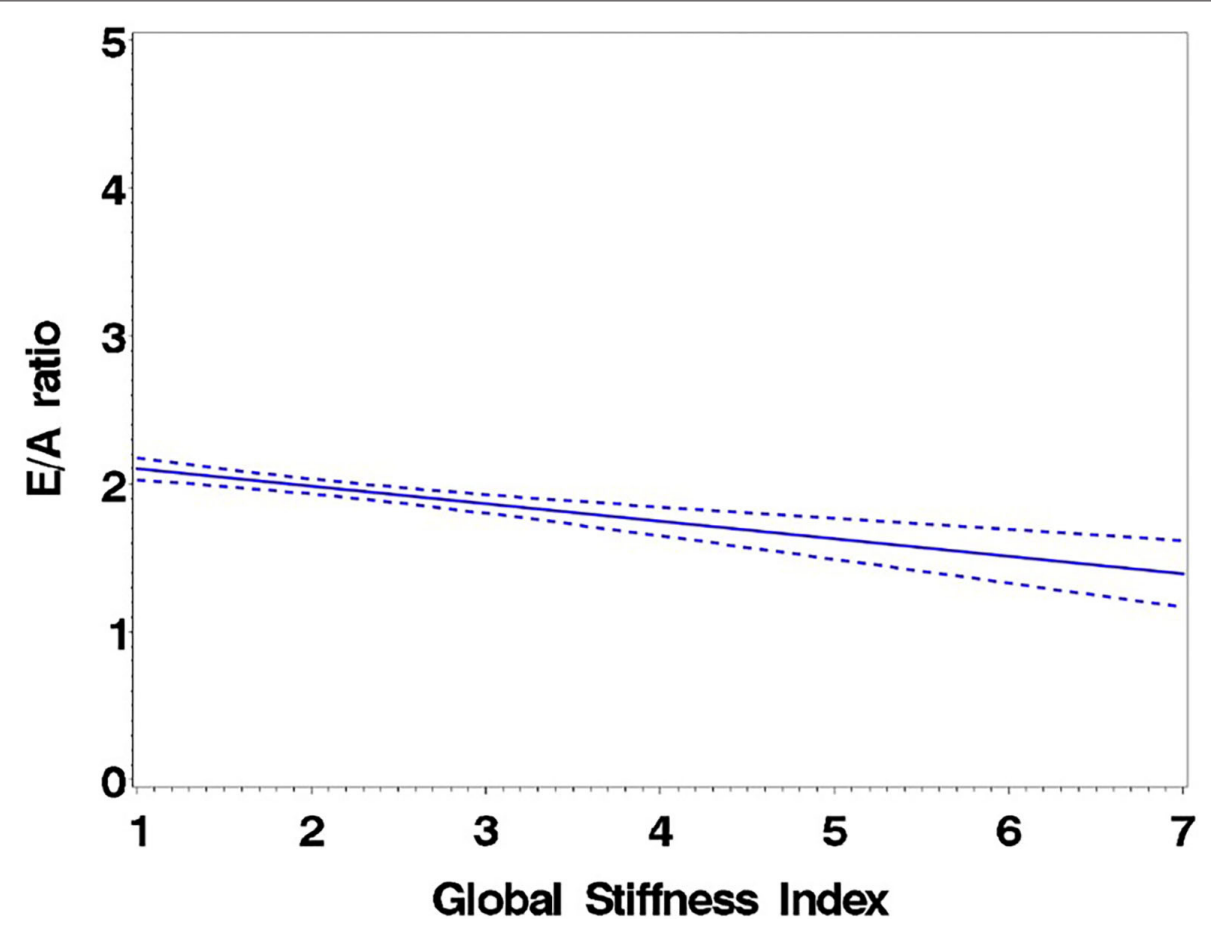

FIGURE 3 | Regression of $e^{\prime} / a^{\prime}$ average on the Global Stiffness Index (mean with 95\% confidence limit). $R^{2}=0.29$; $P$ for slope differs from zero $<0.0001$. 
TABLE 3 | Independent determinants of diastolic function.

\begin{tabular}{lcccc}
\hline Variable & LAD/ht & $\boldsymbol{E} / \boldsymbol{A}$ & $\mathbf{e}^{\prime} / \mathbf{a}^{\prime *}$ & $\boldsymbol{E} / \mathbf{e}^{\prime *}$ \\
\hline Intercept & 1.73 & 1.48 & 1.73 & 1.67 \\
Presence of T2MD & & -0.079 & & 0.072 \\
GSI & 0.029 & -0.049 & -0.032 & $\mathrm{NS}$ \\
Male sex & & & 0.058 & \\
BMl z-score & & -0.029 & -0.051 & 0.060 \\
Age (years) & & -0.013 & -0.017 & \\
SBP z-score & & & & 0.072 \\
HR (beats/min) & & -0.0067 & -0.0075 & \\
LDL (mg/dl) & & & -0.00075 & \\
CRP (mg/dl) & 0.0052 & & & \\
$\boldsymbol{R}^{\mathbf{2}}$ & $\mathbf{0 . 4 0}$ & $\mathbf{0 . 1 6}$ & $\mathbf{0 . 2 9}$ & $\mathbf{0 . 2 3}$ \\
\end{tabular}

All models $p \leq 0.0001$ and all parameters $p \leq 0.05$.

${ }^{*}$ Average of septal and lateral TDI velocities.

All measures of diastolic function are unitless ratios.

Adult studies have demonstrated that increased pulse pressure (a crude surrogate for arterial stiffness) is independently predictive of not only diastolic dysfunction (15-17) but also heart failure with preserved ejection fraction $(18,19)$. In addition, carotid artery wall stiffness $(20,21)$ and aortic compliance, a similar parameter, positively correlate with LV diastolic function (22). Similar to our results, increased PWV is independently associated with diastolic dysfunction in patients with hypertension (23), type 2 diabetes (24), clustered CV risk factors (25), and suspected coronary artery disease (26, 27). Measures of wave reflection including augmentation index are also associated with diastolic dysfunction (28) and LV filling pressure $\left(E / e^{\prime}\right)(9)$. Although an association cannot prove causality, investigators have proposed that as cardiac output falls with worsening diastolic function, neurohumoral activation, and vasoconstriction increase vessel tone to maintain mean arterial pressure and thereby increase vascular smooth muscle mass, tone, and fibrosis, resulting in increased stiffness (29). A direct relationship between neurohumoral activation and increased carotid stiffness has been demonstrated in subjects with heart failure (30). It is also possible that increased pulse wave velocity generates an earlier reflected wave in the cardiac cycle, increasing late systolic afterload, affecting thickthin myofilament interactions and crossbridge dissociation, and leading to impaired relaxation $(31,32)$. The importance of increased arterial stiffness in determining diastolic function is seen in studies of normo- and hypertensive adults, where relaxation assessed with tissue Doppler varies inversely with afterload and vascular stiffness (31). Measurement of ventriculararterial coupling (VAC $=$ ratio of arterial elastance to endsystolic elastance) is also finding increasing usage as VAC predicts outcomes in adults with cardiac disease and heart failure (33). Our study provides a different method to evaluate the relationship between arterial and cardiac function.

Few data are available examining the relationship between arterial stiffness and diastolic function in adolescents. Our previous work demonstrated that increased left ventricular mass was associated with higher arterial stiffness (9), and carotid intima media thickness was associated with reduced systolic strain in healthy youth and those with obesity and T2DM (11). One small study found a relationship between left atrial strain (reflecting diastolic dysfunction) and measures of insulin resistance in obese children (34). Bradley et al. found both increased arterial stiffness and diastolic dysfunction in a group of adolescents with type 1 diabetes mellitus, but did not evaluate the association between the two factors (35). In a later study of children with type 1 diabetes, endothelial function (brachial flowmediated dilation), which is associated with arterial stiffness, was inversely correlated with isovolumic relaxation time, another echocardiographic measure of diastolic function (36). Arterial stiffness has also been associated with elevated LVM in youth after repair of coarctation (37-39). Altered wave reflections leading to increased afterload on the heart has been proposed as a mechanism explaining this observation in youth with a history of coarctation repaired at a young age (40).

Adult studies have also examined the impact of metabolic syndrome (41) and T2DM (42) on arterial stiffness and diastolic function. Roes et al. (41) used MRI to evaluate diastolic dysfunction and found increased PWV and impaired LV diastolic function in subjects with metabolic syndrome, regardless of blood pressure. However, the relationship between PWV and diastolic dysfunction was not examined. Sharman et al. (1) found central pulse pressure, reflecting central arterial stiffness similar to PWV, but not brachial pulse pressure, reflecting stiffness of medium muscular artery, independently predicted diastolic dysfunction in subjects with T2DM. They concluded that increased central stiffness, possibly due to amplified pressure wave reflections, was one potential etiology of the observed abnormalities in LV diastolic function in patients with T2DM. Our work extends the observations of a relationship between arterial aging and diastolic function to youth who are healthy, have uncomplicated obesity, or have obesity-related T2DM.

Many studies have employed exercise interventions to improve arterial parameters. Adult studies have shown a positive association between exercise training and improvement in endothelial dysfunction in adults with both insulin resistance (43, $44)$ and T2DM $(44,45)$. The study by Okada et al. actually saw a decreased rate of cardiovascular events in those participating in the exercise program (45). Similarly, exercise training has been found to improve endothelial function (as measured by FMD) in adolescents with obesity $(46,47)$ and T2DM (48). Some studies have attempted to reverse cardiac dysfunction, with a few demonstrating improved left ventricular diastolic function in obese adults following successful weight loss $(49,50)$. The effect of lifestyle modification on diastolic function has not been studied extensively in youth. However, the above findings suggest that the implementation of an exercise program in obese and diabetic patients may be an appropriate investment of health care dollars to decrease future risk of cardiovascular disease.

\section{LIMITATIONS}

Our cross-sectional design does not allow us to determine the time sequence for the development of changes in arterial stiffness and cardiac diastolic function. As a result, we cannot speculate about causality and cannot precisely determine whether increased arterial stiffness preceded the development of diastolic 
dysfunction or if the reverse is true. In addition, we do not know if they developed simultaneously.

Because of the original study design, our population contains a large proportion of obese subjects and subjects with T2DM that may limit the generalizability of our findings to other populations. Furthermore, both adiposity and the presence of T2DM were important determinants of diastolic function. We were neither able to assess the duration of obesity nor is the duration of T2DM certain, as the earliest phase may be asymptomatic and go unrecognized.

There may also have been other non-measured confounders (for example, activity pattern and fitness level) that affected the vascular-cardiac relationship. However, our findings are similar to results obtained in adults with known cardiovascular risk factors. Finally, equipment and expertise in collecting ultrasound measures of carotid artery stiffness and non-ultrasound measures of arterial stiffness may not be readily available to many pediatric care providers, thus limiting the applicability of the GSI calculation to the clinical setting.

\section{CONCLUSIONS}

We conclude that lower diastolic function is seen in youth with increased arterial stiffness independent of traditional CVD risk factors. Arterial stiffness likely contributes to reduction in diastolic function by increased pulse pressure and LV afterload. Screening for arterial stiffness and diastolic dysfunction in obese or T2DM adolescents may identify youth at increased risk for developing early CVD and provide the temporal opportunity for normalization of pre-clinical disease.

\section{DATA AVAILABILITY STATEMENT}

The raw data supporting the conclusions of this article will be made available by the authors, without undue reservation.

\section{REFERENCES}

1. Virani SS, Alonso A, Benjamin EJ, Bittencourt MS, Callaway CW, Carson $\mathrm{AP}$, et al. Heart disease and stroke statistics-2020 update: a report from the American Heart Association. Circulation. (2020) 141:e139-596. doi: 10.1161/CIR.0000000000000757

2. Brzyzkiewicz H, Konduracka E, Gajos G Janion M. Incidence of chronic heart failure with preserved left ventricular ejection fraction in patients with hypertension and isolated mild diastolic dysfunction. Pol Arch Med Wewn. (2016) 126:12-8. doi: 10.20452/pamw.3257

3. Kane GC, Karon BL, Mahoney DW, Redfield MM, Roger VL, Burnett JC, et al. Progression of left ventricular diastolic dysfunction and risk of heart failure. JAMA. (2011) 306:856-63. doi: 10.1001/jama.2011.1201

4. Benfari G, Miller WL, Antoine C, Rossi A, Lin G, Oh JK, et al. Diastolic determinants of excess mortality in heart failure with reduced ejection fraction. JACC Heart Fail. (2019) 7:808-17. doi: 10.1016/j.jchf.2019.04.024

5. Wan SH, Vogel MW, Chen HH. Pre-clinical diastolic dysfunction. J Am Coll Cardiol. (2014) 63:407-16.3934927. doi: 10.1016/j.jacc.2013.10.063

6. Tran AH, Flynn JT, Becker RC, Daniels SR, Falkner BE, Ferguson M, et al. Subclinical systolic and diastolic dysfunction is evident in youth with elevated blood pressure. (2020) 75:1551-6. doi: 10.1161/HYPERTENSIONAHA.119.14682

\section{ETHICS STATEMENT}

The studies involving human participants were reviewed and approved by IRB committee, Cincinnati Children's Hospital Medical Center. Written informed consent to participate in this study was provided by the participants' legal guardian/next of kin.

\section{AUTHOR CONTRIBUTIONS}

PK and EU designed the study, collected the data, performed data analyses, and contributed to the manuscript. NM, JH, and $\mathrm{RM}$ created the initial draft of the manuscript and contributed to final edits. All authors contributed to the article and approved the submitted version.

\section{FUNDING}

This study was supported by the National Institutes of Health (National Heart, Lung, and Blood Institute) grants R01 HL076269 (CV Disease in Adolescents With Type 2 Diabetes) and R01 HL105591 (CV Aging Study) and partially funded by the National Center for Research Resources and the National Center for Advancing Translational Sciences, National Institutes of Health, through grant 8 UL1 TR001425.

\section{ACKNOWLEDGMENTS}

We would like to acknowledge the work of the entire Cardiovascular Disease in Type 2 Diabetes Study team. We would also like to thank the participants of the Cardiovascular Disease in Type 2 Diabetes Study and their families, without whose support this study would not be possible.

7. Shah AS, Khoury PR, Dolan LM, Ippisch HM, Urbina EM, Daniels SR, et al. The effects of obesity and type 2 diabetes mellitus on cardiac structure and function in adolescents and young adults. Diabetologia. (2011) 54:722-30. doi: 10.1007/s00125-010-1974-7

8. Chirinos JA, Bhattacharya P, Kumar A, Proto E, Konda P, Segers P, et al. Impact of diabetes mellitus on ventricular structure, arterial stiffness, and pulsatile hemodynamics in heart failure with preserved ejection fraction. J Am Heart Assoc. (2019) 8:e011457 doi: 10.1161/JAHA.118.011457

9. Einarsen E, Gerdts E, Waje-Andreassen U, Naess H, Fromm A, Saeed S. Association of increased arterial stiffness with diastolic dysfunction in ischemic stroke patients: the Norwegian Stroke in the Young Study. $J$ Hypertens. (2020) 38:467-73. doi: 10.1097/HJH.0000000000002297

10. Urbina EM, Dolan LM, McCoy CE, Khoury PR, Daniels SR, Kimball TR. Relationship between elevated arterial stiffness and increased left ventricular mass in adolescents and young adults. J Pediatr. (2011) 158:715-21. doi: 10.1016/j.jpeds.2010.12.020

11. Mehta S, Khoury PR, Madsen NL, Dolan LM, Kimball TR, Urbina EM. Arterial thickness and stiffness are independently associated with left ventricular strain. J Am Soc Echocardiogr. (2018) 31:99-104. doi: 10.1016/j.echo.2017.10.002

12. Flynn JT, Kaelber DC, Baker-Smith CM, Blowey D, Carroll AE, Daniels $\mathrm{SR}$, et al. Clinical practice guideline for screening and management of high 
blood pressure in children and adolescents. Pediatrics. (2017) 140:e20171904. doi: 10.1542/peds.2017-1904

13. Abhayaratna WP, Marwick TH, Smith WT, Becker NG. Characteristics of left ventricular diastolic dysfunction in the community: an echocardiographic survey. Heart. (2006) 92:1259-64. doi: 10.1136/hrt.2005.080150

14. Redfield MM, Jacobsen SJ, Burnett JC Jr, Mahoney DW, Bailey KR, Rodeheffer RJ. Burden of systolic and diastolic ventricular dysfunction in the community: appreciating the scope of the heart failure epidemic. JAMA. (2003) 289:194202. doi: 10.1001/jama.289.2.194

15. Xiong J, Yu X, Yu S, Bai B, Xu H, Ji H, et al. Comparison of central and peripheral hemodynamics in association with left ventricular diastolic dysfunction in the community-based elderly Chinese. J Am Soc Hypertens. (2017) 11:366-75 doi: 10.1016/j.jash.2017.04.009

16. Peterson VR, Woodiwiss AJ, Libhaber CD, Raymond A, Sareli P, Norton GR. Cardiac diastolic dysfunction is associated with aortic wave reflection, but not stiffness in a predominantly young-to-middle-aged community sample. Am J Hypertens. (2016) 29:1148-57. doi: 10.1093/ajh/hpw052

17. Cauwenberghs N, Knez J, Tikhonoff V, D'Hooge J, Kloch-Badelek M, Thijs $\mathrm{L}$, et al. Doppler indexes of left ventricular systolic and diastolic function in relation to the arterial stiffness in a general population. J Hypertens. (2016) 34:762-71. doi: 10.1097/HJH.0000000000000854

18. Hundley WG, Kitzman DW, Morgan TM, Hamilton CA, Darty SN, Stewart $\mathrm{KP}$, et al. Cardiac cycle-dependent changes in aortic area and distensibility are reduced in older patients with isolated diastolic heart failure and correlate with exercise intolerance. J Am Coll Cardiol. (2001) 38:796-802. doi: 10.1016/S0735-1097(01)01447-4

19. Weber T, Auer J, O'Rourke MF, Punzengruber C, Kvas E, Eber B. Prolonged mechanical systole and increased arterial wave reflections in diastolic dysfunction. Heart. (2006) 92:1616-22. doi: 10.1136/hrt.2005.084145

20. Vriz O, Bossone E, Bettio M, Pavan D, Carerj S, Antonini-Canterin F. Carotid artery stiffness and diastolic function in subjects without known cardiovascular disease. J Am Soc Echocardiogr. (2011) 24:915-21. doi: 10.1016/j.echo.2011.05.001

21. $\mathrm{Hu} \mathrm{Y,} \mathrm{Li} \mathrm{L,} \mathrm{Shen} \mathrm{L,} \mathrm{Gao} \mathrm{H.} \mathrm{The} \mathrm{relationship} \mathrm{between} \mathrm{arterial} \mathrm{wall}$ stiffness and left ventricular dysfunction. Neth Heart J. (2013) 21:222-7. doi: 10.1007/s12471-012-0353-z

22. Gregory AJ, Dobson G. Proximal aortic compliance and diastolic function assessed by speckle tracking imaging. Can J Anaesth. (2013) 60:667-74. doi: 10.1007/s12630-013-9934-6

23. Ikonomidis I, Tzortzis S, Papaioannou T, Protogerou A, Stamatelopoulos $\mathrm{K}$, Papamichael $\mathrm{C}$, et al. Incremental value of arterial wave reflections in the determination of left ventricular diastolic dysfunction in untreated patients with essential hypertension. J Hum Hypertens. (2008) 22:687-98. doi: $10.1038 /$ jhh. 2008.39

24. Soldatos G, Jandeleit-Dahm K, Thomson H, Formosa M, D'Orsa K, Calkin AC, et al. Large artery biomechanics and diastolic dysfunctionin patients with Type 2 diabetes. Diabet Med. (2011) 28:54-60. doi: 10.1111/j.1464-5491.2010.03146.x

25. Luers C, Trippel TD, Seelander S, Wachter R, Hasenfuss G, Lindhorst R, et al. Arterial stiffness and elevated left ventricular filling pressure in patients at risk for the development or a previous diagnosis of HF-A subgroup analysis from the DIAST-CHF study. J Am Soc Hypertens. (2017) 11:303-13. doi: 10.1016/j.jash.2017.03.006

26. Weber T, O'Rourke MF, Ammer M, Kvas E, Punzengruber C, Eber B. Arterial stiffness and arterial wave reflections are associated with systolic and diastolic function in patients with normal ejection fraction. Am J Hypertens. (2008) 21:1194-202. doi: 10.1038/ajh.2008.277

27. Fukuta H, Ohte N, Wakami K, Asada K, Goto T, Mukai S, et al. Impact of arterial load on left ventricular diastolic function in patients undergoing cardiac catheterization for coronary artery disease. Circ J. (2010) 74:1900-5. doi: 10.1253/circj.CJ-10-0283

28. Russo C, Jin Z, Palmieri V, Homma S, Rundek T, Elkind MSV, et al. Arterial stiffness and wave reflection/novelty and significance. Hypertension. (2012) 60:362-8. doi: 10.1161/HYPERTENSIONAHA.112.191148

29. Kitzman DW, Little WC, Brubaker PH, Anderson RT, Hundley WG, Marburger CT, et al. Pathophysiological characterization of isolated diastolic heart failure in comparison to systolic heart failure. JAMA. (2002) 288:214450. doi: 10.1001/jama.288.17.2144
30. Lage SG, Kopel L, Monachini MC, Medeiros CJ, Pileggi F, Polak JF, et al. Carotid arterial compliance in patients with congestive heart failure secondary to idiopathic dilated cardiomyopathy. Am J Cardiol. (1994) 74:6915. doi: 10.1016/0002-9149(94)90311-5

31. Borlaug BA, Melenovsky V, Redfield MM, Kessler K, Chang HJ, Abraham TP, et al. Impact of arterial load and loading sequence on left ventricular tissue velocities in humans. J Am Coll Cardiol. (2007) 50:1570-7. doi: 10.1016/j.jacc.2007.07.032

32. Borlaug BA, Kass DA. Ventricular-vascular interaction in heart failure. Cardiol Clin. (2011) 29:447-59. doi: 10.1016/j.ccl.2011.06.004

33. Ikonomidis I, Aboyans V, Blacher J, Brodmann M, Brutsaert DL, Chirinos JA, et al. The role of ventricular-arterial coupling in cardiac disease and heart failure: assessment, clinical implications and therapeutic interventions. A consensus document of the European Society of Cardiology Working Group on Aorta \& Peripheral Vascular Diseases, European Association of Cardiovascular Imaging, and Heart Failure Association. Eur J Heart Fail. (2019) 21:402-24. doi: 10.1002/ejhf.1436

34. Mahfouz RA, Gomma A, Goda M, Safwat M. Relation of left atrial stiffness to insulin resistance in obese children: doppler strain imaging study. Echocardiography. (2015) 32:1157-63. doi: 10.1111/echo.12824

35. Bradley TJ, Slorach C, Mahmud FH, Dunger DB, Deanfield J, Deda L, et al. Early changes in cardiovascular structure and function in adolescents with type 1 diabetes. Cardiovasc Diabetol. (2016) 15:31. doi: 10.1186/s12933-016-0351-3

36. Ciftel S, Icagasioglu S, Yildiz G, Tekin G, Aydin H. Association of left ventricular diastolic dysfunction with elevated NT-proBNP in type 2 diabetes mellitus patients with preserved ejection fraction: the supplemantary role of tissue doppler imaging parameters and NT-proBNP levels. Diabet Res Clin Pract. (2012) 96:179-86. doi: 10.1016/j.diabres.2011.12.021

37. de Divitiis M, Pilla C, Kattenhorn M, Donald A, Zadinello M, Wallace S, et al. Ambulatory blood pressure, left ventricular mass, and conduit artery function late after successful repair of coarctation of the aorta. J Am Coll Cardiol. (2003) 41:2259-65. doi: 10.1016/S0735-1097(03)00480-7

38. Ou P, Celermajer DS, Raisky O, Jolivet O, Buyens F, Herment A, et al. Angular (Gothic) aortic arch leads to enhanced systolic wave reflection, central aortic stiffness, and increased left ventricular mass late after aortic coarctation repair: evaluation with magnetic resonance flow mapping. J Thorac Cardiovasc Surg. (2008) 135:62-8. doi: 10.1016/j.jtcvs.2007. 03.059

39. Ou P, Celermajer DS, Jolivet O, Buyens F, Herment A, Sidi D, et al. Increased central aortic stiffness and left ventricular mass in normotensive young subjects after successful coarctation repair. Am Heart J. (2008) 155:187-93. doi: 10.1016/j.ahj.2007.09.008

40. Lombardi KC, Northrup V, McNamara RL, Sugeng L, Weismann CG. Aortic stiffness and left ventricular diastolic function in children following early repair of aortic coarctation. Am J Cardiol. (2013) 112:1828-33. doi: 10.1016/j.amjcard.2013.07.052

41. Roes SD, Alizadeh Dehnavi R, Westenberg JJ, Lamb HJ, Mertens BJ, Tamsma JT, et al. Assessment of aortic pulse wave velocity and cardiac diastolic function in subjects with and without the metabolic syndrome: HDL cholesterol is independently associated with cardiovascular function. Diabetes Care. (2008) 31:1442-4. doi: $10.2337 / \mathrm{dc} 08-0055$

42. Sharman JE, Haluska BA, Fang ZY, Prins JB, Marwick TH. Association of arterial wave properties and diastolic dysfunction in patients with type 2 diabetes mellitus. Am J Cardiol. (2007) 99:844-8. doi: 10.1016/j.amjcard.2006.10.045

43. Tjonna AE, Rognmo O, Bye A, Stolen TO, Wisloff U. Time course of endothelial adaptation after acute and chronic exercise in patients with metabolic syndrome. J Strength Cond Res. (2011) 25:2552-8. doi: 10.1519/JSC.0b013e3181fb4809

44. De Filippis E, Cusi K, Ocampo G, Berria R, Buck S, Consoli A, et al. Exerciseinduced improvement in vasodilatory function accompanies increased insulin sensitivity in obesity and type 2 diabetes mellitus. J Clin Endocrinol Metab. (2006) 91:4903-10. doi: 10.1210/jc.2006-1142

45. Okada S, Hiuge A, Makino H, Nagumo A, Takaki H, Konishi H, et al. Effect of exercise intervention on endothelial function and incidence of cardiovascular disease in patients with type 2 diabetes. J Atheroscler Thromb. (2010) 17:82833. doi: $10.5551 /$ jat. 3798 
46. Watts K, Beye P, Siafarikas A, Davis EA, Jones TW, O’Driscoll G, et al. Exercise training normalizes vascular dysfunction and improves central adiposity in obese adolescents. J Am Coll Cardiol. (2004) 43:1823-7. doi: 10.1016/j.jacc.2004.01.032

47. Meyer AA, Kundt G, Lenschow U, Schuff-Werner P, Kienast W. Improvement of early vascular changes and cardiovascular risk factors in obese children after a six-month exercise program. J Am Coll Cardiol. (2006) 48:1865-70. doi: 10.1016/j.jacc.2006.07.035

48. Naylor LH, Davis EA, Kalic RJ, Paramalingam N, Abraham MB, Jones TW, et al. Exercise training improves vascular function in adolescents with type 2 diabetes. Physiol Rep. (2016) 4:e12713. doi: 10.14814/phy2.12713

49. Fenk S, Fischer M, Strack C, Schmitz G, Loew T, Lahmann C, et al. Successful weight reduction improves left ventricular diastolic function and physical performance in severe obesity. Int Heart J. (2015) 56:196-202. doi: 10.1536/ihj.14-261

50. Karimian S, Stein J, Bauer B, Teupe C. Improvement of impaired diastolic left ventricular function after diet-induced weight reduction in severe obesity. Diabetes Metab Syndr Obes. (2017) 10:19-25. doi: 10.2147/DMSO.S124541

Author Disclaimer: The content is solely the responsibility of the authors and does not necessarily represent the official views of the NIH.
Conflict of Interest: EU received grant funding for this project from NIH (NHLBI) R01 HL105591.

The remaining authors declare that the research was conducted in the absence of any commercial or financial relationships that could be construed as a potential conflict of interest.

Publisher's Note: All claims expressed in this article are solely those of the authors and do not necessarily represent those of their affiliated organizations, or those of the publisher, the editors and the reviewers. Any product that may be evaluated in this article, or claim that may be made by its manufacturer, is not guaranteed or endorsed by the publisher.

Copyright (c) 2021 Madsen, Haley, Moore, Khoury and Urbina. This is an open-access article distributed under the terms of the Creative Commons Attribution License (CC $B Y)$. The use, distribution or reproduction in other forums is permitted, provided the original author(s) and the copyright owner(s) are credited and that the original publication in this journal is cited, in accordance with accepted academic practice. No use, distribution or reproduction is permitted which does not comply with these terms. 